\title{
Evaluation of antioxidant efficacy of ethanolic and methanolic extracts from peanut hulls in silver carp oil during accelerated oxidation
}

\author{
Alkassoumi Hassane Hamadou ${ }^{1}$, Yanshun $\mathrm{Xu}^{1}$, Qixing Jiang ${ }^{1}$, Wenshui Xia ${ }^{1}$, Azhari Siddeeg ${ }^{2}$ \\ ${ }^{1}$ Jiangnan University, No 1800, Lihu Road, Wuxi, 214122 Jiangsu, People's Republic of China \\ ${ }^{2}$ School of Food Science, Jiangnan University, Jiangsu, People's Republic of China
}

\section{Email address:}

xiaws@jiangnan.edu.cn (Wenshui Xia)

\section{To cite this article:}

Alkassoumi Hassane Hamadou, Yanshun Xu, Qixing Jiang, Wenshui Xia, Azhari Siddeeg. Evaluation of Antioxidant Efficacy of Ethanolic and Methanolic Extracts from Peanut Hulls in Silver Carp Oil during Accelerated Oxidation. International Journal of Nutrition and Food Sciences. Vol. 3, No. 2, 2014, pp. 104-110. doi: 10.11648/j.ijnfs.20140302.23

\begin{abstract}
The effect of ethanolic and methanolic extracts form peanut hulls of different concentrations $(1200,4800$ and $12000 \mathrm{ppm}$ ) and 200ppm Butylated hydroxylanisole (BHA) on the oxidative stability of silver carp oil was assessed over 28 days period during accelerated oxidation. The progress of lipid oxidation was assessed in terms of Peroxide value (PV), Conjugated diens (CD), Conjugated triens (CT),Free fatty acid ( FFA) and P-anisidine value (AV).The in-vitro tests of ethanolic and methanolic extracts showed strong reducing power, iron chelating activity and diphenyl picryl hydrazyl scavenging ability.The results showed that there were significant differences between treated and control samples at all the concentrations over the storage period.The oil with methanolic extract of Peanut hulls (PHM) showed lower PV,CD, CT,FFA and P-anisidine value than the oil containing ethanolic extracts of Peanut hulls (PHE) at all concentrations investigated. Moreover the oils with 4800 and $12000 \mathrm{ppm}$ PHM and PHE were superior than 200ppm BHA in reducing oxidation .These results suggested that PHE and PHM can be used as potential natural extracts for improving oxidative stability of silver carp oil.
\end{abstract}

Keywords: Peanut Hulls, Antioxidant, Lipid Oxidation, Silver Carp, Anisidine Value

\section{Introduction}

Silver Carp oil is prone to oxidation because it has high content of polyunsaturated fatty acids (PUFA). Oxidation of food lipids causes serious challenges to food processing industry. It leads to the loss of fat soluble vitamins ;offflavors, discoloration and even production of toxins that may cause food poisoning [1]. Due to health benefits associated with the intake of fish oil PUFA, there is a strong need to protect products containing PUFA.The addition of antioxidants to foods is the most efficient means to retard or suppress oxidation of fats. Synthetic antioxidants such as butylated hydroxyl anisole (BHA), butylated hydroxyl toluene (BHT), tert-Butyl hydroquinone (TBHQ) have been used in many countries [2] because of their low cost. However the use of synthetic antioxidants has been associated with food safety and toxicity [3]. There is currently much interest in the identification of safer ,cheaper and effective natural antioxidants especially polyphenols extracted from plant extracts.

Peanut commonly known as groundnut (Arachis hypogaea) is one of the principal agriculture plants in the world. It grown mostly throughout the tropics and subtropics with worldwide annual production of 38 million tons [4]. Besides the production of oil, peanut can be consumed as raw ,roasted, pureed or mixed with others products. Peanut industry generates a huge amount of hulls and skins as waste.The latters are usually burned or used as fertilizers and in animal feed. The antioxidant activity of Peanut byproducts has been investigated by some researchers[5, 6]. Others findings showed also the effectiveness of methanolic extracts from peanuts hulls in the oxidative stability of soy bean and peanut oils [7]."Reference[8]" revealed that peanut skins were efficient in retarding lipid oxidation in sunflower oil. To our knowledge the use of peanut hulls as antioxidant in fish oil has not been yet reported. Therefore the aim of the present study is to use ethanolic and methanolic extract from peanut hulls, waste from peanut industry to protect Silver carp (Hypophthalmichthys molitrix) oil from oxidation. The 
specific objectives are to determine different phenolic compounds present in ethanolic and methanolic extracts from peanut hulls and also the in-vitro assays of these extracts.

\section{Materials and Methods}

\subsection{Chemicals and Reagents}

The chemicals p-Anisidine ;1,1-diphenyl-2picrylhydrazyl (DPPH),butylated hydroxyl anisole and xylenol orange were purchased from Sigma Aldrich Chemicals (Shanghai ,China). All the others chemicals were of analytical grade and obtained from the chemical store of Jiangnan university (Wuxi, China).

\section{Peanut Hulls Extract Samples}

The peanut were obtained from local market in Wuxi (China). The peanut were washed and hand-shelled.The hulls were dried and ground into a fine powder in a Tecator Cemotec 1090 sample Mill. The materials that passed through an 80-mesh sieve were retained, sealed in a plastic bottle, and stored at $4^{\circ} \mathrm{C}$ until used.

Peanut hulls $(5 \mathrm{~g})$ was extracted with $50 \mathrm{ml}$ of different organic solvent (ethanol, methanol, acetone, hexane) in a shaking incubator at room temperature for $24 \mathrm{~h}$. The extract was filtered and the residue was re-extracted under the same conditions. The extraction was repeated twice, the combined filtrates were evaporated to $5 \mathrm{ml}$ in a rotary vacuum evaporator at $40^{\circ} \mathrm{C}$.

\subsection{Determination of Total Phenolic Content (TPC)}

The concentration of total phenolic compounds was determined spectrophotometrically using the procedure described by [9]. Folin Ciocalteu reagent $0.75 \mathrm{ml}$ (1:10 diluted) was added to $100 \mu \mathrm{l}$ of extract and allowed to stand at room temperature for $5 \mathrm{~min}$. Contents were mixed thoroughly and $0.75 \mathrm{ml}$ of sodium bicarbonate $(6 \%)$ was added to the mixture and incubated at room temperature for $90 \mathrm{~min}$. The absorbance was measured at $725 \mathrm{~nm}$ using a spectrophotometer(Shimadzu UV 1100). The content of total phenolic content was determined using a standard curve prepared from Catechin and the results were expressed as mg of Catechin equivalents per gram of Dried Peanut Hulls.

\section{Screening of the Extracts for Antioxidant Activity}

The methanolic and ethanolic extracts of peanut hulls were screened for antioxidant activity by employing three in-vitro systems namely : reducing power ;1,1-diphenyl-2picrylhydrazyl radical scavenging activity and Iron chelating activity.

\subsection{DPPH Radical Scavenging Activity}

The DPPH assay of extract was performed according to the methods of [10] with some modifications .DPPH solution ( $1.5 \mathrm{ml}, 0.1 \mathrm{mM}$ in $95 \%$ ethanol) was mixed with $1.5 \mathrm{ml}$ of extract at final concentration of 800,1600 , $2400,3200,4000 \mathrm{ppm}$. The mixture was shaken and left for 30minutes at room temperature. Absorbance of the resulting solution was measured at $517 \mathrm{~nm}$ using a spectrophotometer (Shimadzu UV 1100). For the blank ,1.5 $\mathrm{ml}$ distilled water was used instead of the sample and sample control was made also for each fraction by mixing $1.5 \mathrm{ml}$ of sample with $1.5 \mathrm{ml}$ of $95 \%$ ethanol .Radical Scavenging capacity was calculated as follows :

$$
\text { DPPH radical scavenging capacity }(\%)=\left(1-\frac{\text { Abs.of samle-Abs.of control }}{\text { Abs.of blank }}\right) \times 100
$$

\subsection{Reducing Power}

The reducing power was determined according to the method of [11] with slight modifications. Sample solution $(2.4 \mathrm{~mL})$ of varying concentrations ( $100,200,300,400$ and $500 \mathrm{ppm})$ was mixed with phosphate buffer $(2.5 \mathrm{ml}, 0.2 \mathrm{M}$, $\mathrm{pH}$ 6.6) and potassium ferrycyanide $(2.5 \mathrm{ml}, 1 \%)$. After the mixture was incubated at $50^{\circ} \mathrm{C}$ for $20 \mathrm{~min}$, trichloroacetic acid $(2.5 \mathrm{~mL}, 10 \%)$ was added and the mixture was centrifuged at $3000 \mathrm{rpm}$ for $10 \mathrm{~min}$. The upper layer of solution $(5 \mathrm{~mL})$ was mixed with distilled water $(4 \mathrm{~mL})$ and ferric chloride $(1 \mathrm{~mL}, 0.1 \%)$ for $10 \mathrm{~min}$, and then the absorbance was measured at $700 \mathrm{~nm}$ against a blank. Increasing absorbance of the reaction mixture indicates increasing reducing power. All tests were performed in triplicate and averaged.

\subsection{Iron Chelating Activity $\left(\mathrm{Fe}^{2+}\right)$}

The iron chelating activity of the extracts was assessed by the modified method of [12].To $1 \mathrm{ml}$ of the extract $(800$, $1,600,2,400,3,200$ and 4,000 ppm) was added $2.7 \mathrm{ml}$ of deionized water and $0.1 \mathrm{ml}$ of $2 \mathrm{mM}$ ferrous chloride. After $3 \mathrm{~min}$, the reaction was inhibited by the addition of 5 $\mathrm{mM}$ ferrozine $(0.2 \mathrm{ml})$. The mixture was shaken vigorously and left at room temperature for $10 \mathrm{~min}$. Absorbance of the resulting solution was measured at $562 \mathrm{~nm}$ using a spectrophotometer (Shimadzu UV ,Tokyo Japan). A blank was run in the same way by using distilled water instead of a sample. Sample control was made for each extract without adding ferrozine. The chelating capacity was calculated as follows

$$
\text { Iron Chelating Activity }(\%)=\left(1-\frac{\text { Abs of sample }- \text { Abs sample control }}{\text { Abs of sample }}\right) \times 100
$$

\subsection{Fish Samples}

Silver Carp (Hypophthalmichthys molitrix) were purchased from local market in Wuxi (China) and transported within 30 minutes in ice boxes to the 
laboratory of school of food Sciences and technology at Jiangnan University (People's Republic of China). The fish were prepared using the handling method, beheaded and skin removed before thoroughly washed with clean water to remove contaminants and unwanted parts. Fish muscle retrieved with care, separating the fillets from the bones. Fish fillets were vacuum packed in $500 \mathrm{~g}$ packages and rapidly frozen at $-46^{\circ} \mathrm{C}$ until needed.

The method of [13] was used for oil extraction. The recovered oil was flushed with nitrogen without further refining and stored at $-46{ }^{\circ} \mathrm{C}$ until used.

\subsection{Oxidative Stability of Silver Carp Oil Supplemented with Peanut Hulls Extracts}

\subsubsection{Sample Preparation}

Triplicate Samples of 1200, 4800 and 12000 ppm of peanut hulls and 200 ppm of butylated hydroxyl anisole were prepared. Each sample was placed in three brown reagent bottles and mixed thoroughly with the fish oil. All the bottles were stored at $60^{\circ} \mathrm{C}$. Control samples in which no antioxidants were used, set with the test samples at the same temperature. Analyses were conducted at 7 days intervals during 28 days for Peroxide value, Conjugated diens, Conjugated triens, Free Fatty acid and P.anisidine value.

\subsubsection{Peroxide Value (PV)}

Peroxides values determinations were performed according to the ferrous oxidation/xylenol orange method [14] . Sample 0.01-0.3 g was mixed in a disposable glass tube with $9.8 \mathrm{ml}$ chloroform-methanol $(7+3, \mathrm{v} / \mathrm{v})$ on a vortex mixer for 2-4 s. Xylenol orange solution $10 \mathrm{mM}(50 \mu \mathrm{l})$ was added and the sample was mixed on a vortex mixer for 2-4 s. Then $50 \mu$ l of iron (II) solution was added, and the sample was mixed on a vortex mixer for 2-4 s. After a $5 \mathrm{~min}$ incubation at room temperature, the absorbance of the sample was determined at $560 \mathrm{~nm}$ against a blank of chloroform -methanol $(7+3, \mathrm{v} / \mathrm{v})$. The peroxide value expressed as milliequivalents of peroxide value per kilogram of sample was calculated using the following formula:

$$
\text { Peroxide Value }=\frac{(A s-A b) \times \mathrm{m}}{55.84 \times m_{0} \times 2}
$$

Where As: Absorbance of the sample; Ab: Absorbance of the blank, $\mathrm{m}=$ slope obtained from the calibration curve, mo $=$ mass in gram of the sample, $55.84=$ atomic weight of iron

\subsubsection{Conjugated Diens (CD) and Conjugated Triens (CT)}

The method proposed by [15] was slightly modified and used for the measurement of CD and CT content in the oil. Samples $(0.02 \mathrm{~g})$ were diluted with isooctane, and the absorbance of the sample was measured against a blank made of isooctane at $233 \mathrm{~nm}$ for CD and $268 \mathrm{~nm}$ for CT. The CD and CT values were calculated from the absorbance values and the final concentration of sample ( $\mathrm{g} / 100 \mathrm{ml}$ ). The results were expressed as CD and CT values computed as follows

$$
\mathrm{CD}=\mathrm{A} / \mathrm{C} * \mathrm{P} \text { and } \mathrm{CT}=\mathrm{B} / \mathrm{C} * \mathrm{P}
$$

Where $\mathrm{A}$ is the absorbance of the sample at $233 \mathrm{~nm}$; $\mathrm{B}$ is absorbance of sample at $268 \mathrm{~nm}$. C denotes the final dilution concentration of the sample $(\mathrm{g} / 100 \mathrm{ml})$; and $\mathrm{P}$ represents the length of the measuring cell $(\mathrm{cm})$.

\subsubsection{Free Fatty Acid (FFA)}

FFA were determined according to the method by [16] .Samples (3g) were dissolved in a $50 \mathrm{ml}$ mixture of neutral ether-ethanol $(1: 1, \mathrm{v} / \mathrm{v})$; the mixture was then shaken by hand. After being cooled to room temperature, the mixture was titrated against potassium hydroxide $(0.01 \mathrm{M})$ using phenolphthalein $(10 \mathrm{~g} / \mathrm{l})$ as an indicator. The FFA value ( $\mathrm{mg} / \mathrm{g}$ ) was calculated according to the following formula :

$$
\mathrm{FFA}(\mathrm{mg} / \mathrm{g})=(\mathrm{V} \times \mathrm{C} \times 56.11) / \mathrm{m}
$$

Where $\mathrm{V}$ is the volume of potassium hydroxide exhausted by the samples $(\mathrm{ml}), \mathrm{C}$ represents the concentration of potassium hydroxide $(\mathrm{mol} / \mathrm{l})$ and $\mathrm{m}$ the mass of the fish oil (g) sample.

\subsubsection{P. Anisidine Value (AV)}

The Anisidine value was determined according the method of [17].Oil sample (0.5- 4g) was weighed accurately in $25 \mathrm{ml}$ volumetric flask. Dissolve and make up to volume with isooctane. Measure the absorbance of the fat solution against pure isooctane at $350 \mathrm{~nm}$ in a glass cell. Pipette $5 \mathrm{ml}$ of the fat solution into a test tube $\mathrm{A}$ and $5 \mathrm{ml}$ isooctane into a test tube B. Add $1 \mathrm{ml}$ of Anisidine reagent into test tubes A and B. Shake vigorously the test tubes and eave in a dark place for $10 \mathrm{~min}$. Measure the absorbance of the test tube A against test tube $\mathrm{B}$ at $350 \mathrm{~nm}$ in a one cell glass. The Anisidine value was calculated according the following formula :

$$
\text { Anisidine Value }=\frac{25(1.2 \times \mathrm{Eb}-\mathrm{Ea})}{W} \times 100
$$

$\mathrm{Ea}$ is the net absorbance of the fat solution, $\mathrm{Eb}$ is the absorbance of the fat-anisidine-solution, $\mathrm{W}$ is the weight of the sample

\section{Statistical Analysis}

All experiments were replicated three times. Each replicate is expressed as mean $\pm \mathrm{SD}$, and ANOVA test (using SPSS 17)was used to compare the mean values of each treatment The significance of difference among the treatment at the end of each time point during the 4weeks storage was determined by analysis of variance (ANOVA) using the one-way ANOVA with Duncan's test $(\mathrm{P} \leq 0.05)$.

\section{Results and Discussion}

\subsection{Extraction Yield}

Table1 shows the extraction yield of the dried peanut hulls with the four organic solvent. The highest yield was obtained with methanol. The efficiency of the solvents on 
the extraction was in the order of methanol $>$ ethanol $>$ acetone $>n$-hexane. According the results, the extraction yield increased with increasing polarity of solvent. This is in agreement with the results reported by [5].

\subsection{Total Phenolic Content (TPC)}

The amounts of total phenolic content of peanuts hulls are exhibited in Table 2.The data showed that peanut hulls contain relatively high level of total phenolic and the organic solvent significantly influenced the extractable phenolic from the hulls. Total phenolic extracted from the peanut hulls extracts ranged from 4.84 (in hexane) to 8.16 (in methanol)mg/g dry hulls. The results suggested that methanol was better for extracting phenolic compounds due to it's high polarity and good solubility for phenolic compounds from plant materials[18,19].This result is in agreement with that of [20] who have reported $7.8 \mathrm{mg} / \mathrm{g}$ of total phenolic content in methanolic extracts of peanuts hulls irradiated with ultraviolet light.

\subsection{DPPH Radical Scavenging Activity}

The scavenging effect of ethanolic and methanolic extracts of peanut hulls on the DPPH radical is shown in (Figure1).The methanolic extracts showed higher DPPH radical scavenging than ethanolic extracts at all the concentration tested. The scavenging effect of the extracts in the range $800-4000 \mathrm{ppm}$ increased with an increasing of concentrations. Methanolic extracts of peanut hulls at concentration of 1600 and 4000ppm exhibited 83.14 and $95.48 \%$ scavenging activity respectively. Ethanolic extracts also at concentration of $4000 \mathrm{ppm}$ exhibited scavenging activity of about $90 \%$.The data agrees the findings of [21] who reported $89.3 \%$ scavenging activity for methanolic extracts of peanut hulls. The results indicate that peanut hulls extracts provoke noticeable scavenging on free radicals and enhance the stability against primary oxidation.

\subsection{Reducing Power}

The reducing power is an index of secondary antioxidative activity. It is associated with the power of certain antioxidant [22].The reducing power of the extracts increased from 0.2035 to 0.8145 for methanol and 0.1417 to 0.44 for ethanol. Similarly to the DPPH radical scavenging activity, the reducing power is dose-dependent (Figure2).

\subsection{Iron Chelating Activity $\left(\mathrm{Fe}^{+}\right)$}

Chelating agents play a paramount role in the stabilization of fatty foods against rancidity .Transition metals $\left(\mathrm{Cu}^{2+}, \mathrm{Fe}^{2+}\right)$ are involved in both initiation and propagation of lipid peroxidation [23]. $\mathrm{Fe}^{2+}$ is the most powerful pro-oxidant among various species of metal ions [10].Therefore chelating ferrous ions often reduces lipid peroxidation.Figure3 Showed the chelating effect of ethanolic and methanolic extracts of peanut hulls extracts on ferrous ions. The chelating activity is concentration dependent and increase with increasing concentration. The peanut hulls extract at $4000 \mathrm{ppm}$ exhibited
79.16 and $71.21 \%$ respectively for methanol and ethanol.

\subsection{Peroxide Value (PV)}

Peroxide value is used to measure primary oxidation products called hydroperoxides. In this study, oxidation degree on silver carp oil samples was evaluated by measuring PV in the absence and presence of antioxidants at $60^{\circ} \mathrm{C}$ for 28 days (Figure 4). PV was in the range 83.04$247.15 \mathrm{meq} / \mathrm{kg}$ for stabilized samples at the end of storage, while a maximum value of $310.21 \mathrm{meq} / \mathrm{kg}$ was recorded for the control. Significant differences $(\mathrm{P}<0.05)$ were found between these values. Based on PV levels determined in this study, there was a significant difference between the ethanolic and methanolic extracts for all concentration tested. Furthermore the antioxidants effects of the extracts at 4800 and $12000 \mathrm{ppm}$ were better than BHA at 200ppm, and with the increase of content of peanut hulls extract, the antioxidant effect was better. Previous studies have reported the antioxidant activity of methanolic extracts of peanuts byproducts in vegetable oils $[7,8]$.This study revealed that peanut hulls plays a key role for fish oil storage.

\subsection{Conjugated Diens and Triens}

In organic chemistry, the term conjugated diene (CD) refers to two double bonds separated by a single bond. This structure is unusual for polyunsaturated fatty acid,hence the presence of $\mathrm{CD}$ in lipids indicate that autoxidation of fatty acid has occurred.When PUFAs containing three or more double bonds undergo oxidation, the conjugation of $\mathrm{CD}$ moieties can be extended to include another double bond resulting in the formation of a conjugated triene (CT) [24]. The measurement of CD and CT is a crucial index for the early stages of peroxidation studies of pure lipids [25]. Figures 5 and 6 show the formation of conjugated diens and triens, respectively in control and silver carp oil supplemented with peanut hulls extract. High contents were observed for control, indicating greater intensity of oxidation. The CD and CT values for the ethanolic and methanolic extracts at 4800 and 12000 ppm were lower than the $\mathrm{CD}$ and $\mathrm{CT}$ of BHA at 200ppm. The results indicated also at equal concentrations of extracts that the $\mathrm{CD}$ and $\mathrm{CT}$ values of the methanolic extracts were lower than that of ethanolic extracts at all concentrations treated. The results exhibited also that the lowest value of $\mathrm{CD}$ and $\mathrm{CT}$ were observed for $1200 \mathrm{ppm}$ (methanolic extract) .The greater the levels of $\mathrm{CD}$, the lower the antioxidant activity of the oils[26].All the stabilized silver carp oil samples showed the formation of CD and CT to a significant level compared to that of control, reflecting the antioxidant efficacy of the peanut hulls extract.

\subsection{Free Fatty Acid (FFA)}

Free fatty acid analysis measures the amount of free acid and reflect the level of FFA in a sample. FFA increases the susceptibility of oil to oxidation and contribute to bitter/soapy flavors, and cause a decrease of acceptability of food by consumers[27]. FFA formation are due to 
hydrolysis of triglycerides and may get promoted by reaction of oil with moisture[28]. Addition of antioxidants has caused significant reductions in FFA of Silver carp oil during 28 days storage as shown in (figure 7). FFA content went on increasing as the storage time increased for all samples. The FFA was significantly higher in the control samples than silver carp oil with antioxidants during the study. Ethanolic and methanolic extracts of peanut hulls at 4800 and 12000 ppm have lower FFA than BHA at 200ppm at all stages. The same extracts at 1200 exhibited higher FFA values than BHA. It is evident from these results that as the content of peanut hulls extract increased, inhibitory effects on FFA also increased considerably. From the present results, it may be concluded that Peanut hulls from 4800 ppm is more effective over longer storage period than BHA.

\subsection{Anisidine Value (AV)}

The measurement of AV is to assess the secondary oxidation products. Secondary stage of oxidation occurs when the hydroperoxides decompose to form carbonyls and others compounds (aldehydes, ketones, alcohols) which are responsible for off-flavors and off-odors of edible oils. AV calculation is among the oldest reliable method for evaluating secondary lipid oxidation .Determination of Anisidine value is based on the color intensity of reaction between p-anisidine and aldehydes that absorbs at $350 \mathrm{~nm}[29]$. Figure 8 depicts the Anisidine value for silver carp oil stabilized with ethanolic extracts, methanolic extracts, BHA and control. The AV of control reached $36.79 \pm 0.462$ after 28 days of storage. The oil treated with methanolic extracts of peanuts hulls at 1200, 4800, $12000 \mathrm{ppm}$ and BHA at $200 \mathrm{ppm}$ were $16.89 \pm 0.205$, $13.03 \pm 0.24,10.12 \pm 0.21$ and $15.11 \pm 0.055$ respectively. While the ethanolic extract of peanut hulls at $1200,4800,12000 \mathrm{ppm}$ were $17.94 \pm 0.088,14.23 \pm 0.1$ and $11.2 \pm 0.145$ respectively. Significant differences were noted between values of treated and control samples. The results demonstrated also that methanolic and ethanolic extracts at 4800 and 12000 ppm showed lower values of $\mathrm{AV}$ than BHA at 200ppm. The AV is slightly lesser in the oil containing methanolic extracts compare to ethanolic extracts. From these results, it can be seen that phenolic compounds from peanut hulls extracts have a strong inhibitory effect against the secondary lipid oxidation.

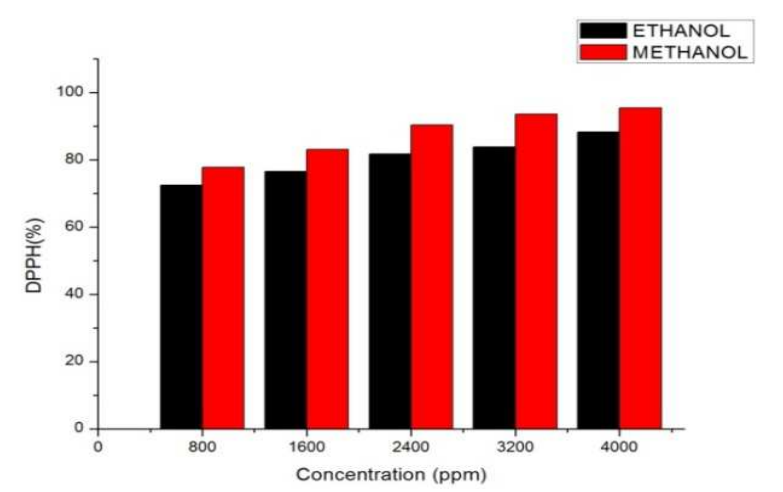

Figure 1. The DPPH radical Scavenging activity of Methanolic and Ethanolic Extracts of Peanut hulls. Results are average of triplicate determinations \pm Standard deviation

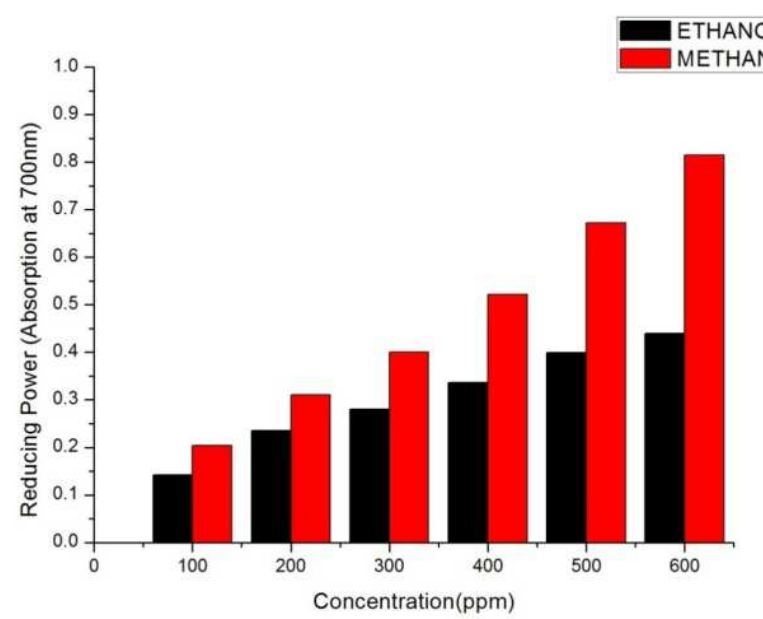

Figure 2. Reducing Power of Methanolic and Ethanolic Extracts of Peanut hulls. Results are average of triplicate determinations \pm Standard deviation

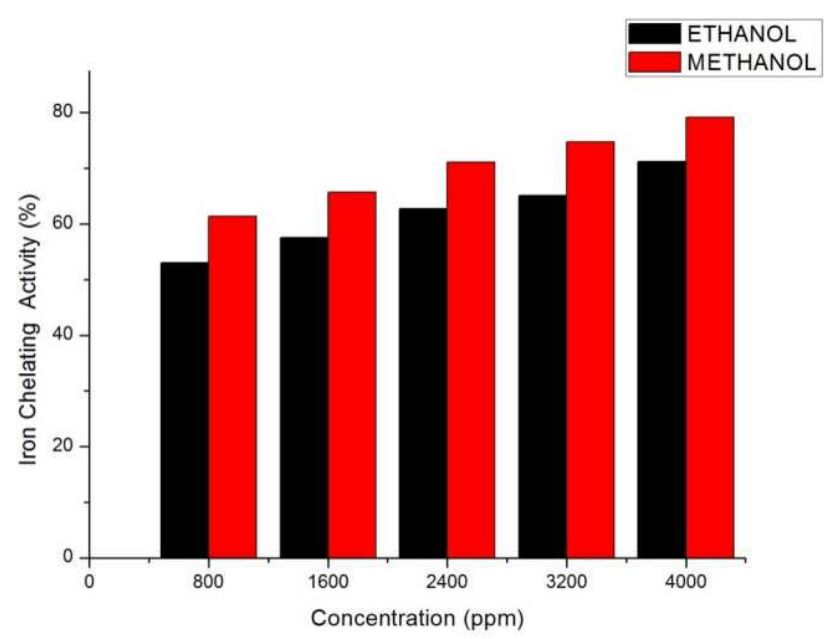

Figure 3. Iron $\left(\mathrm{Fe}^{2+}\right)$ chelating activity of ethanolic and methanolic extracts of peanut hulls. Results are average of triplicate determinations \pm Standard deviation

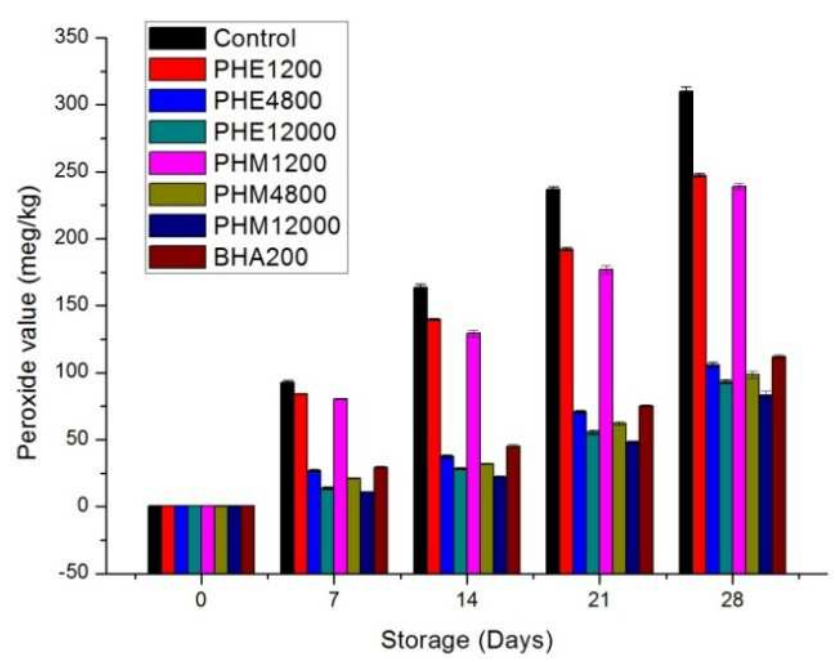

Figure 4. Changes on Peroxide values of Silver carp oil. Results are average of triplicate determination on the same samples \pm standard deviation 


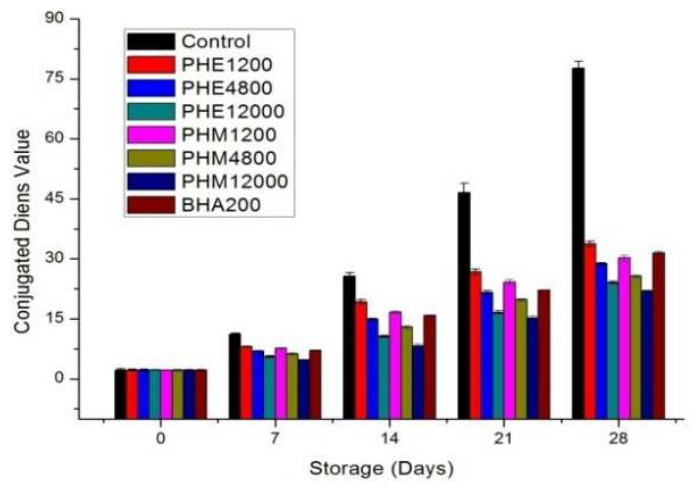

Figure 5. Changes on Conjugated diens values of Silver carp oil. Results are average of triplicate determination on the same samples \pm standard deviation

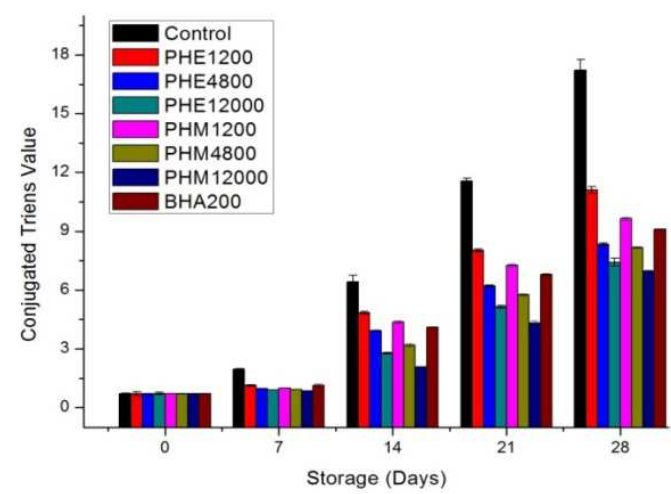

Figure 6. Changes on Conjugated Triens values of silver carp oil.Results are average of triplicate determination on the same samples \pm standard deviation

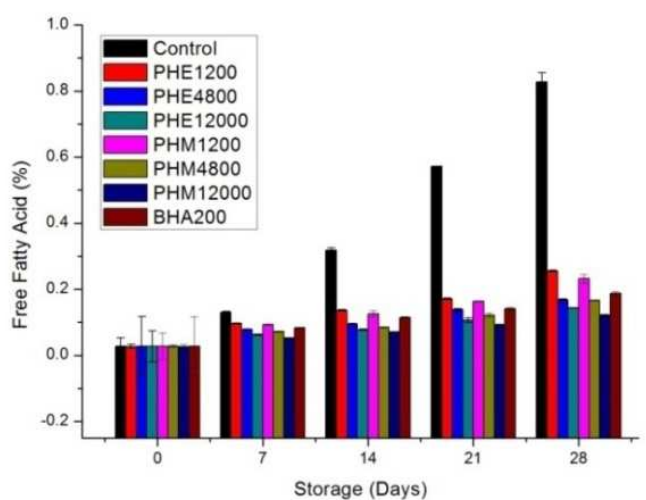

Figure 7. Changes on Free Fatty Acid of Silver carp. Results are average of triplicate determination on the same samples \pm standard deviation

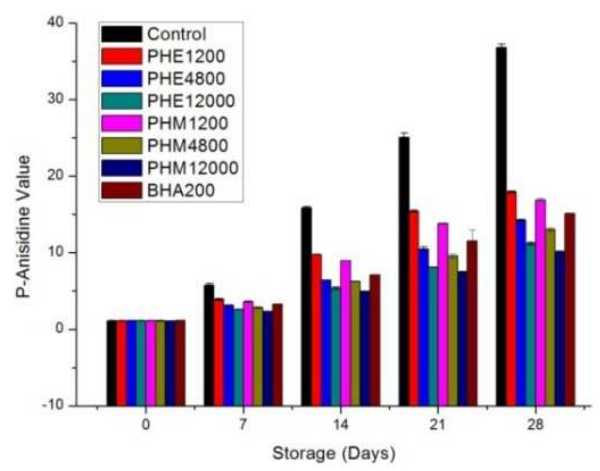

Figure 8. Changes on Anisidine value of Silver carp .Results are average of triplicate determination on the same samples \pm standard deviation
Table 1. Extraction Yield of Dried Peanut Hulls with different organic Solvent

\begin{tabular}{ll}
\hline Solvents & Yield $(\mathbf{m g})$ \\
\hline Ethanol & $100.31 \pm 2.23 \mathrm{~b}$ \\
Methanol & $212 \pm 2.94 \mathrm{a}$ \\
Acetone & $38.12 \pm 2.28 \mathrm{c}$ \\
Hexane & $19.27 \pm 1.61 \mathrm{~d}$ \\
\hline
\end{tabular}

Based on $5 \mathrm{~g}$ of dried peanut hulls for each organic solvent.Means within a column with the same upper letters are not significantly different at $\mathrm{P}$ $<0.05$.

Table 2. Total Phenolic Content of Peanut Hulls ( $\mathrm{mg} / \mathrm{g}$ )

\begin{tabular}{llcl}
\hline Sample & Solvents & $\begin{array}{c}\text { Total Phenolic Content } \\
\text { dried weight) }\end{array}$ & $\mathbf{( m g / g}$ \\
\hline \multirow{4}{*}{ Peanut Hulls } & Ethanol & $7.21 \pm 0.041 \mathrm{~b}$ & \\
& Methanol & $8.16 \pm 0.09 \mathrm{a}$ & \\
& Hexane & $6.81 \pm 0.33 \mathrm{~b}$ & \\
& Acetone & $4.84 \pm 0.3 \mathrm{c}$ & \\
\hline
\end{tabular}

Means within a column with the same upper letters are not significantly different at $\mathrm{P}<0.05$.

\section{Conclusion}

The results demonstrate the potential usefulness of natural antioxidant extracted from peanut hulls extracts for fish oil preservation. Methanolic and ethanolic extracts were greater in total phenolic compounds that are possible antioxidant components from the extracts. Moreover, this study showed that peanut hulls have strong in-vitro antioxidant activities towards DPPH free radical, reducing power and iron chelating activity. At the optimum concentrations of both extracts, methanolic extracts gave lower PV,CD,CT,FFA and $\mathrm{AV}$ values than ethanolic extract. This might be attributed to the higher phenolic compounds acting as antioxidant present in the methanolic extracts. Results observed in our experiment showed that peanut hulls, a waste of peanut processing industry can be used as natural antioxidant for polyunsaturated containing foods.

\section{Acknowledgements}

This research was financially supported by the earmarked fund for China Agriculture Research System (CARS-46-22).

\section{References}

[1] Kamal-Eldin, A., \& Appelqvist, L.-Å. (1996). The chemistry and antioxidant properties of tocopherols and tocotrienols. Lipids, 31(7), 671701.

[2] Sébédioo, J., Kaitaranta, J., Grandgirarda, A., \& Malkk, Y. (1991). Quality assessment of industrial prefried French fries. Journal of the American Oil Chemists Society, 68(5), 299-302.

[3] Chang, S. S., OSTRIC - MATIJASEVIC, B., Hsieh, O. A., \& HUANG, C. L. (1977). Natural antioxidants from rosemary and sage. Journal of Food Science, 42(4), 11021106 
[4] FAOSTAT.(2008).Available at http://fastat.fao.org/

[5] Duh, P.-D., Yeh, D.-B., \& Yen, G.-C. (1992). Extraction and identification of an antioxidative component from peanut hulls. Journal of the American Oil Chemists Society, 69(8), 814-818

[6] Yen, G. C., Duh, P. D., \& Tsai, C. L. (1993). Relationship between antioxidant activity and maturity of peanut hulls. Journal of Agricultural and Food Chemistry, 41(1), 67-70

[7] Duh, P.-D., \& Yen, G.-C. (1997). Antioxidant efficacy of methanolic extracts of peanut hulls in soybean and peanut oils. Journal of the American Oil Chemists' Society, 74(6), 745-748

[8] Nepote, V., Grosso, N. R., \& Guzman, C. (2002). Extraction of antioxidant components from peanut skins. Grasas $y$ aceites, 53(4), 391-395.

[9] Singleton, V., \& Rossi, J. A. (1965). Colorimetry of total phenolics with phosphomolybdic-phosphotungstic acid reagents. American journal of Enology and Viticulture, 16(3), 144-158.

[10] Shimada, K., Fujikawa, K., Yahara, K., \& Nakamura, T. (1992). Antioxidative properties of xanthan on the autoxidation of soybean oil in cyclodextrin emulsion. Journal of Agricultural and Food Chemistry, 40(6), 945-948.

[11] Rodríguez Vaquero, M., Tomassini Serravalle, L., Manca de Nadra, M., \& Strasser de Saad, A. (2010). Antioxidant capacity and antibacterial activity of phenolic compounds from argentinean herbs infusions. Food Control, 21(5), 779785 .

[12] Dinis, T. C., Madeira, V. M., \& Almeida, L. M. (1994). Action of phenolic derivatives (acetaminophen, salicylate, and 5-aminosalicylate) as inhibitors of membrane lipid peroxidation and as peroxyl radical scavengers. Archives of biochemistry and biophysics, 315(1), 161-169

[13] Bligh, E., \& Dyer, W. J. (1959). A rapid method of total lipid extraction and purification. Canadian journal of biochemistry and physiology, 37(8), 911-917.

[14] Meites, L. (1963). Handbook of analytical chemistry. Soil Science, 96(5), 358.

[15] Zuta, P., Simpson, B., Zhao, X., \& Leclerc, L. (2007). The effect of $\alpha$-tocopherol on the oxidation of mackerel oil. Food Chemistry, 100(2), 800-807.

[16] Wang, H., Liu, F., Yang, L., Zu, Y., Wang, H., Qu, S., \& Zhang, Y. (2011). Oxidative stability of fish oil supplemented with carnosic acid compared with synthetic antioxidants during long-term storage. Food Chemistry, 128(1), 93-99.

[17] Hoval House ,Orchard Parade ,Mutton Lane.(1981).Fish oil Bulletin N6 3AR ,England
[18] Siddhuraju, P., \& Becker, K. (2003). Antioxidant properties of various solvent extracts of total phenolic constituents from three different agroclimatic origins of drumstick tree (Moringa oleifera Lam.) leaves. Journal of Agricultural and Food Chemistry, 51(8), 2144-2155.

[19] Peschel, W., Sánchez-Rabaneda, F., Diekmann, W., Plescher, A., Gartzía, I., Jiménez, D., Lamuela-Raventos, R., Buxaderas, S., \& Codina, C. (2006). An industrial approach in the search of natural antioxidants from vegetable and fruit wastes. Food Chemistry, 97(1), 137-150.

[20] Duh, P.-D., Yeh, D.-B., \& Yen, G.-C. (1992). Extraction and identification of an antioxidative component from peanut hulls. Journal of the American Oil Chemists Society, 69(8), 814-818.

[21] Yen, G. C., \& Duh, P. D. (1994). Scavenging effect of methanolic extracts of peanut hulls on free-radical and active-oxygen species. Journal of Agricultural and Food Chemistry, 42(3), 629-632.

[22] Jayaprakasha, G., Singh, R., \& Sakariah, K. (2001). Antioxidant activity of grape seed $(<\mathrm{i}>$ Vitis vinifera $</ \mathrm{i}>)$ extracts on peroxidation models in vitro. Food Chemistry, 73(3), 285-290

[23] Wang, J., Yuan, X., Jin, Z., Tian, Y., \& Song, H. (2007). Free radical and reactive oxygen species scavenging activities of peanut skins extract. Food Chemistry, 104(1), 242-250

[24] Corongiu, F. P., \& Banni, S. (1994). Detection of conjugated dienes by second derivative ultraviolet spectrophotometry. Methods in enzymology, 233, 303-310

[25] Dekkers, J. C., van Doornen, L. J., \& Kemper, H. C. (1996). The role of antioxidant vitamins and enzymes in the prevention of exercise induced muscle damage. Sports Medicine, 21(3), 213-238.

[26] Shahid Chatha, S. A., Anwar, F., Manzoor, M., \& Rehman Bajwa, J.-u. (2006). Evaluation of the antioxidant activity of rice bran extracts using different antioxidant assays. Grasas $y$ aceites, 57(3), 328-335.

[27] Aubourg, S. P., Rey-Mansilla, M., \& Sotelo, C. G. (1999). Differential lipid damage in various muscle zones of frozen hake (Merluccius merluccius). Zeitschrift für Lebensmitteluntersuchung und-Forschung A, 208(3), 189193.

[28] Frega, N., Mozzon, M., \& Lercker, G. (1999). Effects of free fatty acids on oxidative stability of vegetable oil. Journal of the American Oil Chemists' Society, 76(3), 325-329.

[29] Laguerre, M., Lecomte, J., \& Villeneuve, P. (2007). Evaluation of the ability of antioxidants to counteract lipid oxidation: Existing methods, new trends and challenges. Progress in Lipid Research, 46(5), 244-282. 